\title{
Web-based collaboration in individual care planning challenges the user and the provider roles - toward a power transition in caring relationships
}

This article was published in the following Dove Press journal:

Journal of Multidisciplinary Healthcare

8 December 2014

Number of times this article has been viewed

\section{Jorunn Bjerkan ${ }^{1,2}$ \\ Solfrid Vatne ${ }^{3}$ \\ Anne Hollingen ${ }^{4}$}

'Norwegian Research Centre for Electronic Health Records (EHR), Medical Faculty, Norwegian University of Science and Technology, Trondheim,

${ }^{2}$ Faculty of Health Science, NordTrøndelag University College, Levanger, ${ }^{3}$ Faculty of Health Science, Molde University College, ${ }^{4}$ Møre og Romsdal Hospital Trust, Molde, Norway
Correspondence: Jorunn Bjerkan Norwegian University of Science and Technology/Nord-Trøndelag University College, Høgskolen i Nord-Trøndelag, PO Box 250I, NO-7729 Steinkjer, Norway Tel +4748606679 Email jorunn.bjerkan@hint.no
Background and objective: The Individual Care Plan (ICP) was introduced in Norway to meet new statutory requirements for user participation in health care planning, incorporating multidisciplinary and cross-sector collaboration. A web-based solution (electronic ICP [e-ICP]) was used to support the planning and documentation. The aim of this study was to investigate how web-based collaboration challenged user and professional roles.

Methods: Data were obtained from 15 semistructured interviews with users and eight with care professionals, and from two focus-group interviews with eight care professionals in total. The data were analyzed using systematic text condensation in a stepwise analysis model.

Results: Users and care professionals took either a proactive or a reluctant role in e-ICP collaboration. Where both user and care professionals were proactive, the pairing helped to ensure that the planning worked well; so did pairings of proactive care professionals and reluctant users. Proactive users paired with reluctant care professionals also made care planning work, thanks to the availability of information and the users' own capacity or willingness to conduct the planning. Where both parties were reluctant, no planning activities occurred.

Conclusion: Use of the e-ICP challenged the user-professional relationship. In some cases, a power transition took place in the care process, which led to patient empowerment. This knowledge might be used to develop a new understanding of how role function can be challenged when users and care professionals have equal access to health care documentation and planning tools.

Keywords: integrated care, patient participation, empowerment, role transition, system testing, web-based collaboration, Norway

\section{Introduction}

This study explores the ways in which traditional roles of health service users and care professionals were challenged by web-based collaboration in individual care planning. We used data from a larger research project on a web-based tool for care planning called "SamPro", conducted by the hospital trust in central Norway.

The "individual care plan" (ICP) as a concept has been established in several countries, where multidisciplinary and cross-organizational care planning are recognized in concepts such as "patient-centered care", "shared care", "coordinated care", and "integrated care". ${ }^{1-4}$ In Norway, initiatives were taken in the late 1990s to address the acknowledged lack of coordinated care, in response to demands from the public and from politicians for improved care and better coordination of the care provided. National and international political trends supported these demands. A requirement to promote ICPs was incorporated into the Norwegian health care legislation and 
in the Patient Rights Act in 2001..$^{5}$ ICPs were included in the Act related to social services in $2005 .{ }^{6}$ The intention of specifying this requirement in the legislation was to ensure a structured way of planning to encourage user-centered care and thereby to improve the quality of care. Previously, care planning had been accomplished through ordinary patient records, discharge letters, and informal meetings or phone contacts. The scope of an ICP may include different aspects of the user's daily life at a summary level, and therefore takes account a variety of user needs. This new model of cooperation is intended to foster changes in the roles between care professionals and users of the health services, with greater participation by users in care planning and management. No default template was required for the plan apart from the main principles for ICPs specified in Norway's health and social care legislation (Table 1).

The ICP is an overarching plan: a tool supplementing each professional's plans, which does not replace the patient records, but is intended to strengthen the coordination between care professionals and the patient.

\section{A web-based system for ICP: SamPro}

The electronic ICP (e-ICP) is a web-based tool where participants access the ICP document and planning process via the Internet using encrypted log-on procedures on their own mobile device. This means that users and care professionals

Table I Principles of ICPs as stated in Norwegian legislation

Users who need long-term and coordinated care are entitled to a care plan. There is to be only a single ICP per user.

User consent is mandatory for establishing an ICP.

User participation in planning is emphasized.

A named plan coordinator is appointed for each individual plan. This task may be covered by any one of a variety of care professionals - often nurses employed by municipal health services. ${ }^{7}$

RGs are often established, but they are not mandatory. An RG may comprise the coordinator, the user, and a number of named care professionals, and sometimes the user's family members.

Life areas covered by the ICP include health care, work or education, finance and housing, social life, and other life situations, depending on each user's needs.

An ICP identifies key goals and the resources, objectives, and tasks necessary for meeting different aspects of the user's needs. The plan indicates the distribution of responsibility between the user and the different professionals, and a timetable for action. ${ }^{7,8}$

The plan document is available to external care professionals only if the user's approval has been obtained.

The municipalities have a statutory responsibility to review each ICP at least annually. They report regularly on the number of service users who have been offered an ICP, and who have accepted it. ${ }^{9}$

Abbreviations: ICP, individual care plan; RGs, responsibility groups. can interact or collaborate electronically across organizational boundaries or locations. The e-ICP is a supplementary and structured tool based on the individual patient's needs, supporting responsibility group (RG) meetings and everyday human interaction in care planning.

The e-ICP system described in this article, "SamPro", was developed through a joint venture project between the hospital trust in mid-Norway and the system vendor Visma to meet the statutory requirements by enabling efficient care planning and management. The hospital trust wanted a system for its region; the vendor was interested in future expansion in other parts of the country. This project aimed to provide access to care plan information across units at both municipal and hospital care levels. The aim was to enable users to participate in this online documentation and communication on equal terms with care professionals. The system was web-based with no need for installation of software or hardware on users' PCs. This system was developed for future use in other parts of the country after being developed and tested in mid-Norway municipalities and hospitals. Additional web-based functionality beyond the statutory requirements included activity logs, SMS, and an internal email module. ${ }^{10}$ The SMS functionality was used for log-on procedures and for alerts of participant log-on for plan updates. The Document module included the required needs assessment goals and actions as well as a timeline for plan actions and evaluation of each action. The use of computer-based support for preference-based care planning is increasing. Research shows that such support can improve user-centered care and patient outcomes, ${ }^{11,12}$ and might also contribute to power transition in health care relationships.

\section{Transition of power in new health care relationships}

In recent decades, the paternalistic role of user and care professionals has been challenged. For instance, both new public management in public services and movements to promote the rights of users, such as patient and public involvement, have questioned the ways in which care and treatment is provided for people with disabilities or health care needs. ${ }^{13,14}$ Freire introduced the concept of "empowerment", aimed at policy movements for citizen rights and freedom of the individual. ${ }^{15}$ In the 1980s, Rappaport developed an individual psychological concept for community psychology stating, "Empowerment is the mechanism by which people, communities and organizations gain mastery over their lives." ${ }^{16}$ Associated with user involvement, empowerment involves participating in processes of sharing something in common 
with others and in activities that increase people's ability to make choices for themselves, which implies consciousnessraising and capacity building. ${ }^{17,18}$ Users' movement out of an unbalanced relationship can be seen as an individual power transition. However, embracing empowerment means making a paradigm shift which is often difficult because the traditional approach to care is embedded in the training and socialization of most health care professionals. ${ }^{19}$ Research also confirms that the level of user involvement or sharing of real power with the users in care planning is still low. Care professionals experience difficulty in establishing cooperation with users or in adopting the idea of real power transition..$^{20,21}$ In this study, we focus on the philosophy of ICPs and specifically on the roles of users and of care professionals, described in the Norwegian White Paper "From Patient to Citizen". ${ }^{22}$ For health care providers, the implementation of ICPs is a journey from a paternalistic professional role in a hierarchical organization model toward a new asymmetric and multi- or even trans-organizational model of care. ${ }^{23,24}$ The consequences of such a shift will probably influence transitions toward more balanced power in the collaboration and decision process between users and professionals, but success seems to be influenced by various prerequisites.

Meleis defines transition as a passage or movement from one condition or state to another, which can lead to the development of new models and organizational systems, as well as to health-illness transition. ${ }^{24}$ Since implementation of ICPs requires both a new level of planning and changes in user-professional relationships, it is an example of both organizational transition and health-illness transition. It may include new patterns of behavior and mastering of new web-based technology, by both users and care professionals. With reference to international research, Schumacher and Meleis suggested that one indicator of successful transition is the achievement of skilled performance, competence, and the new behavior required in the new situation. In addition, a feeling of well-being with the interpersonal relationship, here between care professionals and users, is important. Success is also dependent on a realistic expectation of the outcome from those involved. The quality and effectiveness of the planning that occurs before and during the testing and implementation of a new model, such as an e-ICP system, are conditions that can influence the success of a power transition. Several studies refer to stress and emotional distress, linked with relational conflicts, feelings of insecurity, being overwhelmed, and defeated. Negative feelings may result in unwillingness to take the risks or in actual avoidance of participation. ${ }^{25}$
Transition theory highlights the importance of understanding transition from the perspective of those involved in the process. However, research dealing with the concept of role transition focuses mainly on the health care professionals' roles, with patients or users mentioned as the recipients of the improved quality of care. ${ }^{26-28}$ Few research projects discuss transition as it affects both users and professionals in a common context. Two studies of the interactions of patients and pharmacists ${ }^{29,30}$ conclude that there is a need for improved congruence between the parties, which is a focus of this study.

\section{Primary objective}

The primary objective of this study was to investigate the user-professional roles in health care and the ways in which these roles are challenged through electronic collaboration in care planning. The research question was: "In what way was the role of care professionals and users challenged during implementation of web-based collaboration in individual care plans?"

\section{Research design}

This is a qualitative study using data obtained during the SamPro implementation project. The study lasted from May 2005 to July 2007. Participants in RGs - users and care professionals who had actively participated in the testing of the web-based system in the "SamPro" project - were asked to take part in interviews. Both individual interviews and focus-group interviews were conducted; we chose what was possible to carry through and what would give most value to this study. We arranged focus-group interviews among coordinators of RGs at one test site because they had regular meetings discussing testing experiences and challenges. They had established an open dialog which we wanted to include in our study because we believed this would enrich the result. In the mental health context, it was not appropriate to organize focus-group interviews. For parents, time was restricted, and we could not expect them to prioritize such a group meeting. For example, we had to go to one family home in order to conduct the interview because this was the only possibility to arrange a meeting.

\section{Methods Setting and participants}

The setting for the study consisted of five municipalities in the Central Norway region chosen by the regional hospital trust. Participants were drawn from three pilot sites and their affiliated hospitals. 
The main inclusion criterion for users was entitlement to an ICP. ${ }^{6}$ All adult users and the majority of child users had more than 2 years' experience of ICP paper-based plans. In this study, the term "users" refers both to adult service users aged 18 or more and to parents of children with disabilities who were part of the study. Adult users had severe psychiatric diagnoses, while child users had various disabilities, which entitled them to coordinated care. When it is appropriate to distinguish between these two groups of users, they are referred to as "parents" and "adult users". The main inclusion criterion for care professionals was their participation in RGs established for the support of the users included in the study. A common inclusion criterion was access to a computer with an Internet connection, and, for users, a personal cell phone for encrypted log-on information. The staff members who contributed to an ICP were drawn from different professional groups in a variety of health and social care organizations, so we have referred to them using the general term "care professionals". This term applies both to the coordinators for RGs and to the other professionals listed in Table 1. The care professionals' background was health education at the bachelor's level or higher. Most of the professionals were nurses; some were teachers and preschool teachers, social care officers, and physiotherapists; and a few were physicians and psychologists. There are some instances in this article when a distinction must be made between the RG coordinators and other professionals, who are then described as "non-coordinators".

Local project leaders at the three SamPro project sites recruited participants and established RGs in their municipalities. The participants, both users and care professionals, were trained in use of the SamPro tool for managing the ICP for half a day, with individual follow-up if necessary. The system vendor offered helpdesk services to the project leaders. No participants withdrew from the study.

\section{Ethical considerations}

We obtained permission for the study from the Norwegian Social Science Data Services, and reported the study to the Regional Committee for Medical Research Ethics. All personal identifiers have been removed or disguised, so the patients/ persons described are not identifiable and cannot be identified through the details of the story. Patients or parents of child patients in the pilot testing project were informed about the study when they joined the testing project, and they were asked to sign consent forms for participating in this study. The patients and parents controlled the e-ICP system access for included RG participants and researchers. Mental health nurses with dialogical competence interviewed vulnerable adult patients.

\section{Data collection and analysis}

We collected data through individual interviews and focusgroup interviews, as shown in Table 2. The interviews were based on semistructured interview guides. ${ }^{31-33}$ Table 3 shows the main questions in the interview guides.

The time spent in individual interviews ranged between 10 minutes and 3 hours; on average they took 1.5 hours. The shorter interviews were limited by the user's condition at the time. In one interview, both parents of a child user participated. Individual interviews were conducted at the end of the study period. ${ }^{34} \mathrm{Six}$ focus-group interviews, three in each of the groups, were conducted during the autumn of 2005. Each focus-group interview lasted approximately 2 hours. The authors of this paper conducted the interviews.

Video recording was preferred for practical transcription reasons, but a few individual interviews were tape-recorded due to available equipment in these situations. All interviews were transcribed verbatim, and discussed among the researchers afterward.

Data analysis was performed using systematic text condensation, according to the stepwise model presented

Table 2 Study context and data collection

\begin{tabular}{|c|c|c|c|}
\hline Study context & Informants & Sample & Data \\
\hline Site I: County I: two town municipalities ${ }^{\mathrm{a}}$ & Adult users & 10 & Individual \\
\hline \multirow[t]{2}{*}{ One rural municipality } & Coordinators & 1 & interviews \\
\hline & Care professionals & 2 & \\
\hline \multirow[t]{3}{*}{ Site 2: County $2:$ one city municipality ${ }^{\mathrm{a}}$} & Parents of child users & 4 & \\
\hline & Coordinators & 2 & \\
\hline & Care professionals & 1 & \\
\hline \multirow[t]{3}{*}{ Site 3: County 3: one town municipality } & Parents of child users & 1 & \\
\hline & Coordinators & 1 & \\
\hline & Care professionals & 1 & \\
\hline \multirow[t]{2}{*}{ Site I: County I } & Coordinators & 8 persons in & Focus group \\
\hline & & 2 different groups & interviews \\
\hline
\end{tabular}

Notes: ${ }^{a}$ Town municipality, $<50,000$ inhabitants; city municipality, $>50,000$ inhabitants. 
Table 3 Interview guide, key questions

Individual interviews

How do you regard your role as a user/care professional in relation to the health care system?

Do you think your role has changed through use of the SamPro system?

Focus-group interviews How did the coordinators and users collaborate in the ICP?

What challenges did they experience? Did the user have a greater co-decisionmaking role when using the e-ICP?

Abbreviations: ICP, individual care plan; e-ICP, electronic individual care plan.

by Malterud. ${ }^{35}$ The analysis started with naive reading of the set of the transcribed individual interviews and of the focus-group interviews separately, one by one, to gain a general impression and to discern the preliminary themes. Examples of preliminary themes included To take responsibility or be responsible, To be in control, Coping in life.

From the naive reading, "meaning units" representative of the research questions were found, for example,

As long as you dare to write down the bad things you clearly

see what is good and what is bad.

Being aware of what is important to work with.

The interviews and focus-group interviews were further analyzed as a single coherent piece of text. From the meaning units and the preliminary themes, the coding continued into themes, with small changes from the preliminary outline.

Themes were further condensed into overarching themes, and detailed with subgroups. Four main themes were generated from the text without any theoretical criteria:

- the proactive users speaking about themselves and their care professionals;

- the reluctant users speaking about themselves and their care professionals;

- the proactive care professionals speaking about themselves and their users;

- the reluctant care professionals speaking about themselves and their users.

Finally, the analysis was completed, presenting the generated descriptions, with quotations from the integrated text illustrating the subthemes. The main themes form the structure of the presentation of the results.

\section{Results}

The mental health patients were aged between 21 and 68; five had completed military service, three had a part-time job, and only one had had further education after secondary school. Participating parents were aged from 30 to 50; all except one had higher education and all were in part-time or full-time jobs. Both users and care professionals expressed clear opinions about their own role as participants in use of the e-ICP as well as their RG partners; users about care professionals; and care professionals about users. No coherence was found between the users' sociodemographics/illness symptoms and activity in the e-ICP. In the following paragraphs, the subthemes are shown in italics to improve readability.

\section{The proactive user}

The proactive users generally emphasized the benefits of online access to the care plan and to the process overview. They participated actively in the collaboration by sending SMS messages to their RG participants, reading and editing their plan or commenting on care professionals' planned actions.

The adult users used phrases such as

I am my own boss now

or

The game is in my part of the field.

They expressed a sense of comfort and safety in the situation, and a perception of greater control. Two adult users even wanted to be their own coordinators, as they felt that by using this tool they could manage their own care planning.

The proactive user roles were grouped into themes such as co-responsibility user, everyday user, and self-therapeutic user. Following examples indicate how these groups were manifested. Data from the interviews showed that a number of users started to act more proactively in the determination of their own plan, in different ways. Some focused on their everyday life, for example, making appointments for the next RG meeting by using the internal messaging module. These everyday users generally sought to make just enough use of the SamPro system to benefit from minimal expenditure of time and effort.

In contrast, a couple of adult self-therapeutic users used the plan to write down their psychological problems and difficult feelings, which they then brought into conversations with their coordinators or psychotherapist:

I write it down in my plan when I want to! I just get it right out of my head! Wow.

Proactive users were aware that greater participation was accompanied by an increased level of joint responsibility. The co-responsible users took a leading part in system 
implementation and planning processes. As both users and care professionals participated in joint online process and system training, users sometimes saw a lack of skills among professionals involved both in care planning and in computing. Many users had just as good, or better, knowledge of computer and Internet use as had the care professionals. In a few RGs, these users took the role of system superusers:

Don't you worry: I will come to an evening shift and teach you how to use this tool.

Users stated that, in well-functioning groups, care professionals took initiatives and responded to requests in a satisfying way. They trusted the care professionals involved and participated according to their own needs and wishes.

When care professionals withdrew from their part of the planning, proactive users took on tasks and responsibility normally vested in the professionals. Users also took responsibility for their impact on the working hours of the professionals by their awareness of SMS availability, taking into consideration that care professionals might not be willing to respond to messages when they were off duty. Planning disagreements among care professionals also became more visible, not just in meetings but now also in the web-based activities. Users accessed logs and commented on whether or not the professionals participated in plan collaboration as expected.

Some users therefore compensated by increasing their participation in their own RGs due to a lack of trust in the professionals involved.

\section{The proactive care professional}

Generally, the care professionals involved in the RGs did not regard their role as much changed by their engagement in web-based collaboration. They saw themselves as being the main initiative takers in the planning process, as specified by the regulations relating to ICP. They took on the plan-managing role as usual, and described their consciousness of this role, taking the professional role in planning appropriate to their expertise and position. They perceived their performance of documentation tasks as a means of ensuring appropriate provision of care. The coordinator took responsibility for the completeness of the overall plan, and non-coordinators for their specific parts. There was diversity of opinion about the distribution of responsibility and workload between coordinators and non-coordinating professionals. The coordinators said they had the main collaborative responsibility in their RG, but they had to work hard to get their colleagues involved in collaboration, even though everyone had equal online access and responsibility to carry out the planned activities. They felt a solitary responsibility for keeping collaboration going and for documenting the tasks within the plan. The coordinators had an additional role as system superusers, and they were in charge of system training in their RG.

If they lacked knowledge about system use or planning, they actively searched for support to learn more about how to plan properly using this web-based tool. They said that the extra work led to long working hours. They asked for a better distribution of responsibility among all care professionals involved.

The proactive care professionals generally expressed confidence in the users' role and participation. They did not perceive users with greater competence in using computers than their own as threatening their professional role in the collaboration. Nevertheless, care professionals took on a protective role as they expressed that they were worried about some users' capacity and disclosure; they were afraid users would reveal more private information in the plan documentation than they would be comfortable with later.

The proactive care professionals said they worked hard to motivate users to take part in the collaborative process. They wanted users to document their real needs and goals, but they often felt they had little success in engaging users to take ownership of the planning process.

Web-based collaboration extended their communication opportunities with their fellow RG participants, and care professionals liked this facility. However, they still seemed to prefer using the established communication lines that they had been used to before e-ICP was introduced: message books in the kindergarten, telephone calls, ordinary SMS, and postal letters.

\section{The reluctant user}

Reluctant users generally commented that they did not reject the web-based tool as a solution for care planning, but looked forward to a future, better-functioning tool. In the meantime they preferred or felt forced to stay reluctantly in a role of being uncommitted.

Exhausted reluctant users regarded e-ICP participation as an extra burden in their lives. When adult users could not manage to obtain access to the system or they had problems using the system for their own purposes, they felt helpless. In some cases, this feeling of helplessness was due to technical issues, a lack of expertise, or lack of coping with their illness. The group of parents in particular expressed that they had little extra time to spend: 
This is not going to be another Net banking solution where

I do the work for them

Adult users also expressed a feeling of decreased coping if in difficult periods they were not capable of the level of planning participation that they expected of themselves. Like parents with high care burdens, these users showed less interest in plan management. Their energies were reserved for everyday coping, and an active role in web-based planning became an extra burden.

In some RGs, adult users felt overruled by care professionals in their planning efforts. A few without a computer at home even claimed that:

They don't let me see my plan.

Users also experienced that a few care professionals declined to participate because they found receiving SMSs at all hours a burden, even when no reply was needed. In several instances, users had to put pressure on care professionals to make them take on their commitment to care planning. In these situations, users felt they were ignored by the professionals involved.

\section{The reluctant care professional}

Several care professionals said they felt uncomfortable in their lack of expertise in using this new tool. After training, they rarely accessed the tool; they became passive in planning, and forgot how to use the SamPro system in the interval between one log-on and the next. They were uncommitted to the planning process in their RG. Non-coordinating professionals relied extensively on the plan coordinator. Reluctant care professionals focused on the SMS availability they were exposed to; they felt their working time, in particular, their private life and spare time were being interrupted. The data showed that reluctant care professionals did not pay attention to users' participation in e-ICP planning or to users' coping in the process. Nor did these care professionals reflect on the need of less skilled users for training or follow-up. Users were regarded as having no plan ownership.

These care professionals doubted that adult users understood the motivation for using the web-based tool, and believed they could only cope with simple tasks in planning. Reluctant care professionals stated that users involved had a "no-ownership role" in their own plan.

\section{Discussion}

The main finding in this study was that the roles of both users and care professionals were challenged in terms of the understanding of the patient/professional role in their
e-ICP interactions. Some of the users and the professionals developed a "proactive role" enabled by the possibilities of the new tool, which influenced the plan process. Others remained in a passive role, "reluctant users" or "reluctant care professionals", in spite of web-based collaboration opportunities. The data also showed a correspondence between the different user and care professional roles, but no differences connected to age, sex, or levels of education. Figure 1 provides a summary model of the function of care providers and users. Arrows indicate the potential relationships between users and care professionals and what attitudes they showed toward a web-based collaboration.

We saw the greatest transfer of power in the patient/ provider relationship in the group we called "proactive users". This power transition was made possible by two main preconditions: 1) the new cross-organizational model of care that necessitated preparation of a multidisciplinary and collaborative ICP for service, enabling user involvement in ICP development, ${ }^{8}$ and 2) the use of SamPro, which, for the proactive users and care professionals, stimulated activity and collaboration as well as knowledge and shared responsibility. Both knowledge and responsibility are important elements in the transition of power toward patient empowerment. ${ }^{19}$ Using SamPro enabled some users to work on their plan both independently and together with their care professionals. Through the web-based access to the plan documents and to the planning process in the SamPro system, a proactive user might run the planning with little support from the care professionals. This was also the situation in some RGs, where the professionals involved were not synchronized in their planning activities, and users assumed some of the responsibilities for coordinating the plan. We even saw instances where users had effectively become their own plan coordinators. ${ }^{12}$ Users took on a proactive planning role for different reasons; some simply had an attitude of taking responsibility, for some there was a need for everyday scheduling of activities, and others found it therapeutic. Whatever the reason, these users took some control of the planning, gained a sense of ownership of their plan, and acted as empowered users. All these examples illustrate forms of power transition.

Planning was accomplished well in RGs established between proactive users and proactive care professionals, taking account of factors that were important to the user and to other participants. Users were enabled to conduct planning by assuming co-responsibility to whatever extent that they wanted or needed. This process was complemented by care professionals who carried their part of the planning 


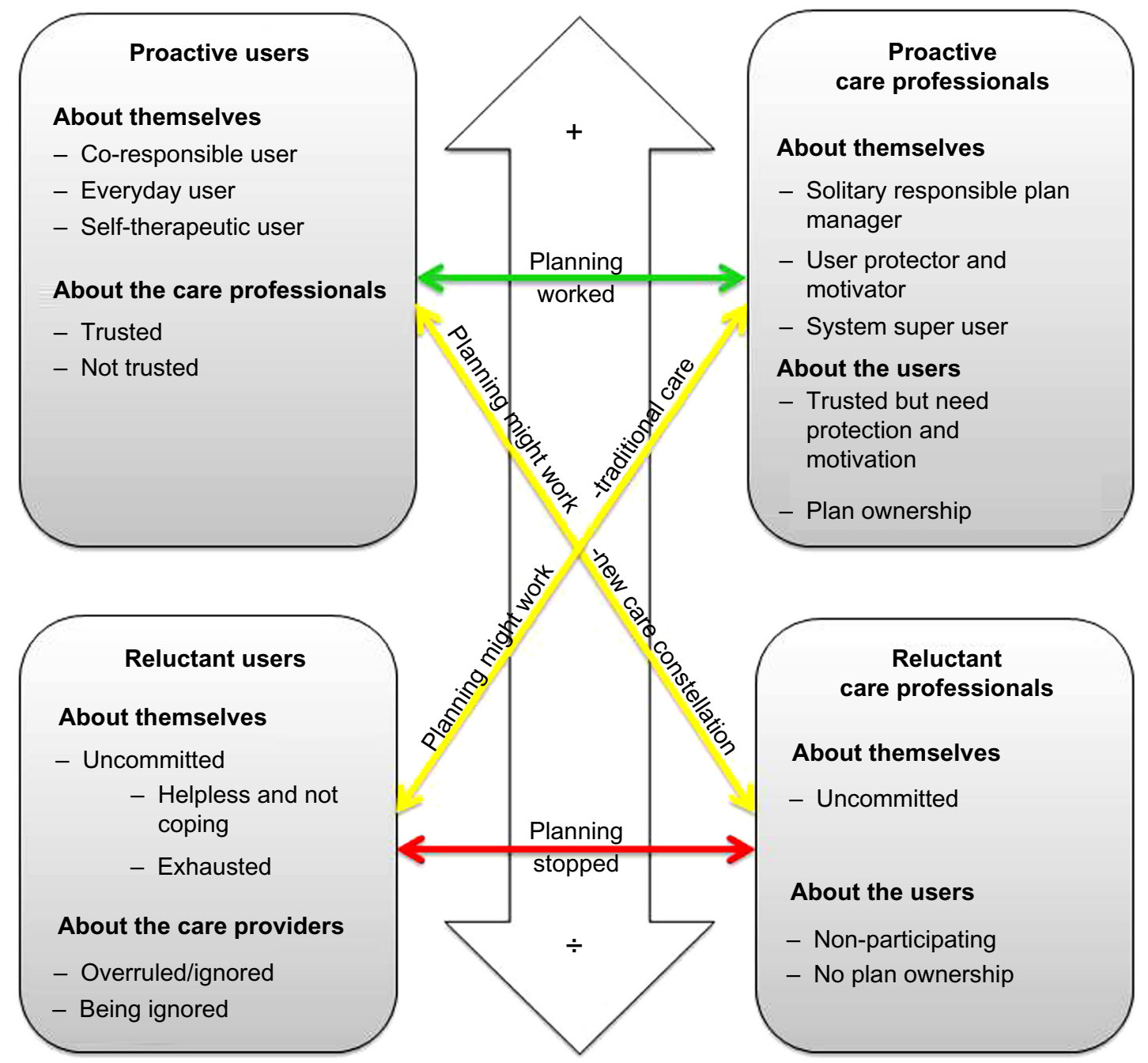

Figure I Transition of power in care professional versus user roles in e-ICP. Abbreviation: e-ICP, electronic individual care plan.

responsibility in terms of various co-responsibility models supporting both users who preferred a self-therapeutic approach and those who focused on daily planning. This flexibility was possible due to the organizational model that web-based access enabled. All the participants, users as well as care professionals, could access the shared collaborative platform and the documentation involved. This flexibility led to the development of reciprocal confidence and trust between the different participants involved in each e-ICP, which resulted in more equality of power. This constellation met the requirements of both ICP thinking and the prevailing political ideal of user involvement and patient empowerment, with the care professionals taking on a flexible, supportive, coaching role. ${ }^{36}$

As has been noted in the literature, ${ }^{25}$ this transition of power depended on either users or their collaborating care professionals developing the technical skills required, and acting with skilled role performance and competence. ${ }^{20}$ It was also necessary that both parties saw the plan process as meaningful. To be system superusers was an additional task or function for both users and professionals; this was not known from previous patient-professional constellations. By taking a proactive attitude, they accomplished this extra task and learned from whichever participant was most skilled in the use of web-based systems and the e-ICP, regardless of whether this skilled person had the role of being the therapeutic expert or the lay user in the care setting. When users took on the superuser task, we saw the development of new performance and user behavior, and a power transition took place. The care professionals, who had been expected to be the expert in the relationship, shifted power toward the lay participant, the user. The patient became an "expert patient", ${ }^{37}$ 
being the group member who was most skilled and competent in ICT system use.

However, when the web-based tool did not function well, and the participants could not realize the potential of the system or the users were too exhausted or too ill to use the tool actively, no transfer of power took place. Under such circumstances, SamPro could be a hindrance for some reluctant participants, and patients might be less instead of more empowered. The tasks of the system superuser increased the workload of the care professionals who undertook them. This sometimes increased reluctance among those who did not have the knowledge or skills to commit to this new task. For care professionals, exposure to SMS alerts for system updates while they were off duty could increase reluctance. The research of Schumacher and Meleis supports this finding, indicating that the achievement of skilled performance, competence, and new behavior required is necessary for successful transition. ${ }^{38}$ This requirement might be an ongoing iterative process, as new technology becomes available and legislation is subsequently updated to address new ways of documenting and communicating patient information.

The data showed that in instances where there was low commitment from both parties, the planning process did not have the driving force on which collaborative processes aiming for growth depend. As some users in this "reluctant" constellation were simply ignored by the uncommitted care professionals, this strengthened the negative attitude to planning in RGs.

Despite the new culture of increased patient empowerment that has developed in recent years and the new opportunities available to users through the web-based solution, users could not be expected to take over planning tasks that were the responsibility of care professionals. ${ }^{39}$ These reluctant users did not have the energy or courage to take on the task of leading their own care planning without support from the care professionals involved. As no one carried out the planning tasks, planning stopped. The expectation had been that ICPs would be established for approximately 3\% of the population in Norway, but studies showed an increase only from $0.5 \%$ in 2005 to $0.58 \%$ in $2010 .^{7,38}$ Professional reluctance, whatever the reasons, might be a problem hindering the expected growth in plans, and the low number does not seem to have been addressed through any legal or organizational reaction.

In paternalistic power distribution in health and social care, the professionals involved are the experts and they supervise the implementation of activities identified for the care users for whom they are responsible. ${ }^{39,40}$ Care professionals are in charge of the process, and users receive and accept the care program, based on the professionals' decisions. The connectivity line in Figure 1 between a proactive care professional and a reluctant user follows this paternalistic approach. ${ }^{41}$ The care users explained to the interviewers that they did not have the capacity needed for proactive participation and consequently they left the care planning to the professionals. We saw in our data that proactive care professionals compensated by taking on actions on behalf of the reluctant users. This behavior does meet one of the purposes of an ICP: to establish a planning group to ease the life situation of the users. In groups where users felt well taken care of, this asynchronous relationship between the user and the care professional might work well, as long as users felt that their needs and requirements were met as they wanted.

We also identified users who felt that they were ignored or overruled by their proactive care professionals. Plans might still be made, even though the users felt they had little voice in the planning process. ${ }^{42}$ This reaction of resignation in response to overruling or ignorance from care professionals has also been reported in and is also recognizable in previous research. ${ }^{43,44}$ Such negative feelings are barriers to participation $^{25}$ and hindrances to power transition.

A nontraditional constellation and a change to former role interpretation were seen in the pairing of a reluctant care professional and a proactive user. In this constellation, the reluctant care professional did not take the expected responsibility or showed a laissez-faire attitude through their lack of commitment in planning. Their partner, the proactive user, was taking on greater planning responsibility than had been intended in the conception of ICPs.

The model of complementary roles of ICP presented in Figure 1 shows various constellations of user involvement, attitudes of care professionals, and power transition. Our data did not show that users wanted the same level of formal responsibility as was required of the care professionals. They wanted to trust the professionals to do their part of the job, but took more initiatives and control than known from other health care constellations. Web-based access made this possible, or compensation for a lack of professional initiatives made it necessary. The user's level of coping and having the time or energy to commit were essential in this instance. Care professionals stated that they were aware of being in charge of the process, even in instances where users stated that the care professionals had not always acted in accordance 
with their level of responsibility. Here, the content of the roles was in transition, bringing more power to the users involved. Instances when users were ignored and were not permitted to see their care plan, while they knew that it should have been available to them on the Internet, could be understood as a clear demonstration of professional power at the expense of user empowerment. The other main purpose of ICP is to increase patient empowerment. ${ }^{8,39}$ Even though the main intention of patient empowerment is to increase user involvement and self-determination, this empowerment role may also be interpreted as involving the right not to participate actively in circumstances where the user's level of fatigue or other lack of capacity is too great. ${ }^{45}$ Users' active choice of noninvolvement is not often discussed in health care politics, which now emphasizes patient empowerment and user involvement. ${ }^{46}$

Discussions of the need for or use of paternalism or professional power in care in relation to patient autonomy and empowerment are common in nursing professional theory. ${ }^{47-49}$ Patient empowerment generally refers to the increase in the strengths of marginalized people, involving development of confidence in their own capacities. Empowerment refers here to the transfer of at least some decision-making power, as we saw in "proactive users". Unless users have the opportunity to make decisions over their own lives, they cannot become independent. ${ }^{17}$ That means that care professionals have to take a step back, limiting their own expectations, and acting more like an equal partner. In international literature, the partner role is presented as an important prerequisite for user cooperation. ${ }^{50-53}$ Daniel describes partnership as a "power with-relation", where integrity and more strength and ability to carry out things are preserved, while equivalence in authority and benefits is maintained. ${ }^{54}$ In the present study, the researcher's collaboration and follow-up support of the individual user can coincide with the description of taking the role of a partner. The results show that user education contributed to an increase in knowledge and skills, which in turn resulted in users who were more knowledgeable. Some users went through a change from being passive recipients to becoming more active partners.

\section{Limitations}

We argue that the validity of this qualitative study relies on the fact that the data answer the research question and that the results correspond with findings from international research. Strengths of the study include the use of both individual and focus-group interviews and the authors' joint activity in performing the steps in the data analysis.
Some weaknesses may be the small sample of informants and the type of participating RGs, representing only two patient groups in one of four health trusts in Norway, as well as the age of the data. The system testing and implementation process limited the possible number of participants due to the demanding schedule of testing and the follow-up needs among the participants. The findings cannot therefore be generalized. However, results from recent studies in Norway ${ }^{13,42,55,56}$ make our findings credible in terms of both the context and date of this study. The use of multiple sites was not seen as a weakness because both system testing and data collection were coordinated. The variation found was identified as either individual or related to the patient groups (children/adults), but not to the testing sites. The care professionals and users interviewed were all participating in the SamPro implementation project and they might therefore be more positive about e-ICP.

\section{Conclusion}

In the use of a web-based system for care plan collaboration, we found that both users and care professionals took upon themselves the role of being proactive or reluctant participants in the planning process, which can be interpreted as a role transition through transition of power, eg, knowledge, responsibility, and a new function. A new pattern revealed in this study was the proactive user who could make planning work despite being paired with reluctant care professionals if the user was given web-based access to the planning tool and their own plan documents. The knowledge from this study might be used to develop a new understanding of how role content and power or the user/care provider relationship can be challenged through equal access by users and care professionals to health care documentation and planning tools. The study also shows the need for technical knowledge and skills among participants in web-based planning. When this was missing, no power transition took place.

More research should be encouraged in order to explore further the tendencies we have revealed; the reasons for proactivity and reluctance should be investigated in greater depth, together with ways to ensure that patients do not become even more isolated or neglected by being paired with nonengaging carers. It is also necessary to determine whether such web-based care planning tools are more suitable for some groups of users than for others. We therefore suggest a more rigorously designed study of how users' sociodemographics (such as sex, age, and level of education), disease, and functional limitations might influence the 
human-human interaction as well as the power transition and users' empowerment in the context of e-ICP.

\section{Acknowledgments}

We thank the participants testing the e-ICP tool, especially the members of the regional project group. The Hospital Trust (CNRHA) represented by the ICT manager, Arild Pedersen, made the project possible and provided additional funding. Thanks are also due to the Masters' students who participated in the project and to Margaret Forbes for improving the language of the article. Finally, our warm thanks go to Ragnhild Hellesø, the reflective supervisor of the first author.

\section{Disclosure}

Jorunn Bjerkan was employed part-time by the Central Norwegian Regional Health Authority (CNRHA) as project manager during testing and implementation of the e-ICP, which was the period of this study. The research and the student's PhD studies were financed and governed by a university grant. Additional funding was received from the CNRHA and Nord-Trøndelag University College to support preparation of this paper. The authors report no other conflicts of interest in this work.

\section{References}

1. Kodner DL, Spreeuwenberg C. Integrated care: meaning, logic, applications, and implications - a discussion paper. Int J Integr Care. 2002;2(4):1-6.

2. Battersby M, Health-Plus-Team. Health reform through coordinated care: SA HealthPlus. BMJ. 2005;330(7492):662-665.

3. Harno K, Nykänen P, Ohtonen J, Seppälä A, Kopra K. Healthcare Information Exchange in Regional eHealth Networks Implications for Initiatives in Advancing Shared Care. International Conference on eHealth, Telemedicine, and Social Medicine, eTELEMED '09, Cancun; 1-7 February 2009. 42-45, IEEE; 2009.

4. Sarrami-Foroushani P, Travaglia J, Debono D, Braithwaite J. Key concepts in consumer and community engagement: a scoping meta-review. BMC Health Serv Res. 2014;14(1):250.

5. Pasient-og brukerrettighetsloven. [Patients'rights act]. Oslo, Norway; 1999/2012.

6. Forskrift om habilitering og rehabilitering individuell plan og koordinator. [Norwegian Ministry of Health and Care Services, Regulations for Rehabilitation, Individual care plan and Coordinator]. Oslo, Norway: Norwegian Ministry of Health and Care Services; 2011.

7. Bjerkan J, Richter M, Grimsmo A, Hellesø R, Brender J. Integrated care in Norway: the state of affairs years after regulation by law. Int $J$ Integr Care. 2011;11:1-8.

8. Normann T, Sandvin JT, Thommesen H, Stultz C, Giskeødegård IK. A holistic Approach to Rehabilitation. Oslo: Kommuneforlaget; 2004.

9. SSB SN. Statistikk ordnet etter emner [Statistics organized by topics]. 2013; Available from: http://www.ssb.no/emner/. Accessed February 22, 2013.

10. Bjerkan J, Hedlund M, Hellesø R. Patients' contribution to the development of a web-based plan for integrated care - a participatory design study. Inform Health Social Care. 2014:1-18.
11. Lau F, Kuziemsky C, Price M, Gardner J. A review on systematic reviews of health information system studies. J Am Med Inform Assoc. 2010;17(6):637-645.

12. Bjerkan J, Alonso A. Patients and professionals in collaborative testing of a web-based tool for integrated care: an evaluation study. Stud Health Technol Inform. 2010;157:66-71.

13. Hansen GV. Samarbeid uten fellesskap, om individuell planer i kommunalt psykisk helsearbeid. [Coordination without Collaboration - About Individual Plans in Municipal Mental Health Services], PhD Thesis, Karlstad: University of Karlstad; 2007.

14. Simonet D. The new public management theory in the British health care system: a critical review. Admin Soc. In press 2013.

15. Freire P. Pedagogy of the Oppressed. New York: Herder \& Herder; 1970.

16. Rappaport J. Terms of empowerment/exemplars of prevention: toward a theory for community psychology. Am J Community Psychol. 1987;15(2):121-148.

17. Chamberlin J, Schene AH. A working definition of empowerment. Psychiatr Rehabil J. 1997;20:43-46.

18. Lewis FM, Glanz K, Rimer BK. Health Behavior and Health Education: Theory, Research, and Practice. San Francisco, CA: Jossey-Bass; 2002.

19. Anderson RM, Funnell MM. Patient empowerment: myths and misconceptions. Patient Educ Couns. 2010;79(3):277-282.

20. Anderson RM, Funnell MM. Patient empowerment: reflections on the challenge of fostering the adoption of a new paradigm. Patient Educ Couns. 2005;57(2):153-157.

21. Storm M, Edwards A. Models of user involvement in the mental health context: intentions and implementation challenges. Psychiatr $Q$. 2013;84(3):313-327.

22. Manneråk S, Brandsnes E, Brattstrøm M, et al. Fra Bruker til Borger. En strategi for nedbygging av funksjonshemmende barrierer [From patient to citizen. Governmental strategy of reducing disabling barriers in Norway]. Olso: Det norske storting, Helsedirektoratet; 2001.

23. Ahgren B, Axelsson R. Evaluating integrated health care: a model for measurement. Int J Integr Care. 2005;5:e01.

24. Brattheim B, Faxvaag A, Toussaint P. When information sharing is not enough. Stud Health Technol Inform. 2011;169:359-363.

25. Schumacher KL, Meleis AI. Transitions: a central concept in nursing. Image J Nurs Sch. 1994;26(2):119-127.

26. Schmitt N. Role transition from caregiver to case manager, part 1 . Lippincotts Case Manag. 2005;10(6):294-302.

27. Schmitt N. Role transition from caregiver to case manager - part II. Prof Case Manag. 2006;11(1):37-46.

28. Holt IGS. Role transition in primary care settings. Qual Prim Care. 2008;16(2):117-126.

29. Guirguis LM, Chewning BA. Role theory: literature review and implications for patient-pharmacist interactions. Res Social Adm Pharm. 2005;1(4):483-507.

30. Worley MM, Schommer JC, Brown LM, et al. Pharmacists' and patients' roles in the pharmacist-patient relationship: are pharmacists and patients reading from the same relationship script? Res Social Adm Pharm. 2007;3(1):47-69.

31. Freeman T. 'Best practice' in focus group research: making sense of different views. J Adv Nurs. 2006;56(5):491-497.

32. Krueger RA. Focus Groups. A Practical Guide for Applied Research. Los Angeles, CA, USA: Sage; 2009.

33. Brinkmann S, Kvale S. Interviews - Learning the Craft of Qualitative Research Interviewing. Los Angeles, CA, USA: Sage; 2009.

34. Dale A, Mason J. Understanding Social Research: Thinking Creatively about Method. Los Angeles, CA: Sage Publications; 2010.

35. Malterud K. Systematic text condensation: a strategy for qualitative analysis. Scand J Public Health. 2012;40(8):795-805.

36. Greenhalgh T. Chronic illness: beyond the expert patient. BMJ. 2009;338(7695):629-631.

37. Heldal F, Tjora A. Making sense of patient expertise. Social Theory Health. 2009;7(1):1-19. 
38. Rambøll Management for Helsedirektoratet. Kartlegging av individuelle planer i landets kommuner. [Survey of Individual Care Plans in Norway]. Oslo: Helsedirektoratet; 2011. Available from: http://helsedirektoratet.no/helse-og-omsorgstjenester/habilitering-rehabilitering/ individuell-plan/Documents/kartlegging-av-individuelle-planer-ilandets-kommuner.pdf.

39. Colombo C, Moja L, Gonzalez-Lorenzo M, Liberati A, Mosconi P. Patient empowerment as a component of health system reforms: rights, benefits and vested interests. Intern Emerg Med. 2012;7(2):183-187.

40. McAllister M, Dunn G, Payne K, Davies L, Todd C. Patient empowerment: the need to consider it as a measurable patient-reported outcome for chronic conditions. BMC Health Serv Res. 2012;12(1):157.

41. Hughes JJ. Organization and Information at the Bed-Side: The Experience of the Medical Division of Labor by University Hospitals' Inpatients [dissertation]. Chicago: University of Chicago, Department of Sociology; 1995.

42. Humerfelt K. Brukermedvirkning $i$ arbeid med individuell plan, -anerkjennelse og krenkelse. [User Participation in the Work of Individual Care Plan, -Acknowledgment and Offense]. Trondheim: Faculty of Social Science, Norwegian University of Science and Technology; 2012.

43. McKinlay JB. Who is really ignorant - physician or patient? J Health Soc Behav. 1975;16(1):3-11.

44. Malterud K, Thesen J. When the helper humiliates the patient: a qualitative study about unintended intimidations. Scand J Public Health. 2008;36(1):92-98.

45. Tritter JQ, McCallum A. The snakes and ladders of user involvement: moving beyond Arnstein. Health Policy. 2006;76(2):156-168.
46. Tritter JQ. Revolution or evolution: the challenges of conceptualizing patient and public involvement in a consumerist world. Health Expect. 2009; 12(3):275-287.

47. Christensen M, Hewitt-Taylor J. Empowerment in nursing: paternalism or maternalism? Br J Nurs. 2006;15(13):695-699.

48. Zomorodi M, Foley BJ. The nature of advocacy vs. paternalism in nursing: clarifying the 'thin line'. J Adv Nurs. 2009;65(8):1746-1752.

49. Orem DE, Taylor SG. Reflections on nursing practice science: the nature, the structure, and the foundation of nursing sciences. Nurs Sci Q. 2011;24(1):35-41.

50. MacGillivary H, Nelson G. Partnership in mental health: what it is and how to do it. Can J Rehabil. 1998;12(2):71-83.

51. Rush B. Mental health service user involvement in England: lessons from history. J Psychiatr Ment Health Nurs. 2004;11(3):313-318.

52. Brown D, McWilliam C, Ward-Griffin C. Client-centred empowering partnering in nursing. $J$ Adv Nurs. 2006;53(2):160-168.

53. Michaelsen R, Vatne $S$, Hollingen A. Koordinatorrollen ved Indviduell plan - fokus på brukermedvirkning og samarbeid. [The role of coordinator in an Individual Plan - focusing patient participance and cooperation]. Norsk Tidsskrift for sykepleieforskning. 2007;4(9):15-28.

54. Daniel LE. Vulnerability as a key to authenticity. Image. 1998;30(2): 191-192.

55. Holum LC. "Individual plan" in a user-oriented and empowering perspective: a qualitative study of "individual plans" in Norwegian mental health services. Nord Psychol. 2012;64(1):45-57.

56. Holum LC. "It is a good idea, but." A qualitative study of implementation of 'Individual Plan' in Norwegian mental health care. Int J Integr Care. 2012;12:30.
Journal of Multidisciplinary Healthcare

\section{Publish your work in this journal}

The Journal of Multidisciplinary Healthcare is an international, peerreviewed open-access journal that aims to represent and publish research in healthcare areas delivered by practitioners of different disciplines. This includes studies and reviews conducted by multidisciplinary teams as well as research which evaluates the results or conduct of such teams or

\section{Dovepress}

healthcare processes in general. The journal covers a wide range of areas and welcomes submissions from practitioners at all levels, from all over the world. The manuscript management system is completely online and includes a very quick and fair peer-review system. Visit http://www.dovepress.com/testimonials.php to read real quotes from published authors. 